\title{
Analysis on the Beauty of Hokkien Songs' Tone and Charm
}

\author{
Zhiyi Bai \\ School of Music and Dance, Quanzhou Normal University, Quanzhou Fujian, 362000, China
}

Keywords: Fujian and Taiwan, Hokkien, Songs, Tone, Charm.

\begin{abstract}
The analysis from the essential attribute, Fujian and Taiwanese folk songs belong to our folk music, is a popular pop songs, to a certain extent reflects the southern region, Taiwan and even Southeast Asia regional culture, Chinese culture is one of the main representatives of local culture. Based on the analysis of the origin of Fujian and Taiwanese songs, this paper focuses on the tune from the charm and beauty of the inquiry these two aspects, hoping to provide appropriate support for the study of Fujian and Taiwanese songs.
\end{abstract}

\section{Introduction}

Hokkien song is a unique part of our language use characteristics of Fujian and Taiwan will be kind of song sung to form a personalized tune and charm in the development process. Hokkien song has some unique regional culture in Fujian and Taiwan, which has a basic social culture, lyricism and popularity more properties in the dissemination of culture in Fujian and Taiwan, strengthening cultural exchanges between Fujian and Taiwan to play an extremely important role. At this stage, with the strengthening of our national strength and international influence of culture, the development of Hokkien song is also growing interest in some of the world music lovers, so be studied at this stage of its charm and beauty of the tune, the song Mining Humanities plot and history, has a certain practical significance [1].

\section{The beauty of Hokkien songs' tone}

Hokkien song as a tune system with unique properties, not only an important standard tune the Beauty, but also reflects the artistic means of this song, it is precisely because of the beautiful tune of song that prompted it has been widely spread by social public welcome.

\section{Beauty of trembling tone}

Trembling tone is generally deep and passionate singing of the song is widely used to convey sorrow and confusion in the song of life emotionally, but also there are some songs to sing inspirational thoughts, showing Fujian and Taiwan people's spirit of unremitting struggle. Such regions from Taiwanese opera and folk absorbed in singing, gradually showing popularization and popular development trend, and this application vibrato in singing the song in the process of showing the beauty is often used to express farewell, tears, lyrical lament and other situations, the emotional song can be perfectly presented [2]. Shake the chamber music concert in the form of characteristic beauty of the song mainly in terms of the tail articulation and rational treatment of the majority of the lyrics. In the course of a specific song to sing in the singer often by means of an elongated tail word vibrato to enhance the beauty of music, which requires the singers have a good grasp of the atmosphere, can be combined in the actual concert during the concert need to promote full use of breath song vibrato line cavity further extended. Fujian and Taiwan in more traditional Taiwanese songs, songs are often able to enjoy the unique style of singing, which is becoming the main features of Hokkien song different from other kinds of music song. 


\section{Beauty of sobbing tone}

Sobbing tone is used to express grief thought in a song, which generally does not have more fixed melodies and figurations accompaniment pattern, with certain uniqueness. Apply it to sing a song of been able to reflect a certain beauty, mainly because of the use of tearful singer full of emotion in the singing process, tearful music can be fully demonstrated the characteristics, access to certain aesthetic experience. Therefore, the required staff should have a certain concert vocal art culture, with its own relatively good singing skills in the process of singing songs full of musical beauty tearful performance [4]. This is applied in a tearful voice singing style Hokkien song after prolonged continuous improvement, the corresponding optimal adjustment to better reflect the emotional content of the song. Fujian and Taiwan Hokkien song in concert during a reasonable application tearful show a unique beauty of South Fujian and Taiwan songs widespread and better development of the foundation.

\section{Beauty of Hokkien song's elegance and common charm}

Listen to the song Fujian and Taiwanese people should be able to feel this one kind of song form generally against civilian's life, the joys and sorrows of life, life, emotions and so on as its theme, will present secular emotional focus. This is more common everyday feelings and thoughts, lack of life cannot be missing something, so although popular songs, but showed no emotion as flavor.

\section{Beauty of common}

South Fujian and Taiwan and Fujian and the songs reflect the life of people in the region, local customs and culture, is a native accent cannot let go, has a unique ideological significance in the minds of the locals. Fujian and Taiwan Hokkien song endless line of people feel the beauty of the chamber, the most important reason is its ability to reflect the people's awareness of local culture, can stimulate people's minds cannot let go of nostalgia. In traditional Taiwanese songs always reflect a tragic characteristics, highlighting the local people in the modern city indulge in feasting frustration. But precisely because it can handed down classic Taiwanese song often thought to urban life full of pathos and helplessness, hence be treated as a period of time is a vulgar song, its dissemination and development are subject to certain restrictions [5]. But this understanding of certain errors, such that the Hokkien song vulgar views generally have a strong subjective, but for analysis from an objective level, Hokkien song reason for being in different regions, different ages and audiences welcome love, the most important reason is its thoughts to convey a kind of inspirational power to inspire people to live and work in constant progress. Hokkien songs from initial development to the final formation of the song kind of a special nature, it is because of its unique beauty can lead vocals resonate with the audience, and then get music viewer's identity.

\section{Beauty of elegance}

In life there are always capable of exhibiting or tough or delicate emotions, and listen to the songs in the process if the song can convey emotion in the people's own emotions and a certain resonance, it will give the impression that a very deep impression. Fujian and Taiwan Hokkien song has the artistic beauty, not only because of its lyrics influenced by local culture itself has a certain beauty, melody is also unique, and the Beauty also tune of artistic beauty is formed to produce a corresponding impact. These songs are full of sad emotions are often able to realistic representation of the people's heart, but in a mournful tunes reflect urban life at the same time in which permeated with some positive thinking, so that people get emotional listening to a song during resonance and, thus, to persevere, dynamic and constantly fighting. Infiltrate a kind of strong cultural thought in Fujian and Taiwanese Hokkien song, whose singing can be so many Taiwanese people's thoughts and feelings passed down from generation to generation, the southern region to promote better cultural heritage and dissemination. Besides singing Taiwanese songs in the beauty has a unique form of emotional catharsis also with the corresponding function can be thought of the human spirit play a relevant role 
of sublimation, the tune of the song of those who appreciate individualized interesting culture, reflects a real tastes.

Hokkien song tune of Fujian and plays an important role in the spread and development of the song, the tune sung from the point of view of art performance, they need to sing with the flexibility of use breath, standard articulation, clean and clear sound, in this be flexible based on the use of the song emphasize exhibit true feelings, prompting the Beauty and tune it to get the full play, to lay the foundation for the development of Fujian and Taiwanese songs. Only with such a unique beauty that prompted Hokkien song after a long period of development to today's society it is still able to be widely recognized by the community welcome. So in the future inheritance Hokkien song should also pay greater attention to the tune of the Beauty to promote the beauty of the tune can be given full play, highlight the song unique personality.

\section{Innovative development and renaissance of Hokkien song at new period}

Chinese pop music in the music, the songs Fujian and Taiwanese although unique and has a certain beauty, with several showing the prosperity and development of the situation, but on the whole, this song kind of has been hovering between the edge and mainstream, especially in today's society music industry development trend showing a decline in the social context, Fujian and Taiwanese songs have already started to show some inheritance crisis in contemporary society. Therefore, at this stage between Fujian and music management departments must pay greater attention to the inheritance and development between Fujian and Taiwan Hokkien song and rehabilitation work, to take certain measures to fine-tune its propagation and transmission of work, corresponding to contribute forces for the modernization of Hokkien songs.

For a long time, the process of succession in the cultural heritage of outstanding traditional concept has been on people's minds to produce deep-rooted influence, did not forget their homeland in life, always maintain a certain national feelings is worthy of recognition and praise, but sometimes it limitations exist in terms of species will lead to ideological creators thought there are some obstacles in the specific process of artistic creation, you cannot play the advantages of their own creation, in essence, is not conducive to the national culture of modernization and development. For Fujian and Taiwanese songs, the current song heritage of the problems in the process is the traditional cultural heritage work restrictions, some of the creators in specific creative practice, even some of the more simple melodies, will find ways to integrate into the local Features traditional folk songs or minor, although such a creative way into the national cultural thoughts, but also limits the value to enhance the song to a certain extent.

In recent years, although the importance of strengthening the Fujian and Taiwan Hokkien song tradition and innovation development efforts, and actively organize some Taiwanese Song Contest in social momentum and expand the influence of Hokkien song heritage work has played a positive role in the corresponding, also contributed to the spread of the continent in Hokkien song changed the pre-existence of the lag situation. However, due to lack of guidance innovative ideas, leading to Song Contest in the packaging and promotion of means and forms are relatively rigid, backward, unable to effectively mobilize the enthusiasm of the masses of the poor inherit and develop practical effect Hokkien song. Meanwhile, in a recent competition organized, Hokkien song writing itself the weaker sense of innovation in the creative process in the song too much emphasis on traditional culture and national integration, but poor penetration of innovative musical elements of consciousness, plus Study Hokkien songs musicians general lack of full understanding of the times in terms of extending the grasp new ideas and traditional culture, and ultimately led to the current of Fujian and Taiwanese original songs still early folk and reflect life as the main content of the new era content urban development, cultural innovation and other aspects of the integration of less cause there are some restrictions audience range of songs.

To Fujian and Taiwan in the new era of Hokkien songs innovation, heritage revival song, should break the shackles of traditional music and heritage of thought, actively introduce and explore new 
forms of music, and with the Hokkien songs perfectly fusion, Fujian and Taiwanese songs explore development opportunities in contemporary society.

The main innovation is to be able to get the better of popular songs and dissemination, in today's society and popular songs in order to give the community recognize the need to further enhance their song fashion. In recent years, Taiwan Hokkien song has begun tentative introduction of Western musical elements, and actively learn from Western thought in the creative process of composing songs in Taiwanese, and using a relatively modern musical style, prompting Hokkien song really changed the original some local flavor, gradually transformed into modern society, the popular music genre, was widely welcomed by the people all over the country.

In particular the process of writing songs, creative people need to be creative thinking and innovation, and in the packaging and promotion of the song, also requires a certain sense of innovation, enhance the artistic value and commercial value of the song, the song can be better to promote the spread of get the community widely recognized. Meanwhile, the soundtrack song innovation aspect, the southern region should actively explore more advanced music ideas, closely follow the trend of the times, targeted adjustments aimed at young people and pursue hobbies, prompting Hokkien song to obtain a relatively wide range of markets, success spread. However, in this process, the music will recognize that the music belongs to the public, and therefore cannot refer only to the music of younger age groups to enjoy demand to be innovative music creation, should also be appropriately referring to appreciate the needs of other groups to ensure that Taiwanese song writing can and appreciation of the standard mass fit. That is, Hokkien song tradition and innovation in contemporary society should meet the needs of youth groups at the same time, an appropriate balance between the need to appreciate the elderly, so Hokkien song can really come into different groups of life and emotional world.

In recent years, along with the community to pay greater attention to Fujian and Taiwan Hokkien song heritage work, Fujian and Taiwan have gradually emerged a number of more outstanding young musicians, their songs in the creative process that can break through traditional thinking bondage, proper integration into the respective elements of modern music in Hokkien song, prompting Hokkien song got better development and heritage. Visible in the next life, as long as the music continued efforts in Fujian and Taiwan, Fujian and Taiwanese songs will usher in a new opportunity for development in the future, access to modernity heritage.

\section{Conclusions}

In the development process of Hokkien song, the song can be obtained in order to ensure a good tradition, it should be the origin and development of the song were analyzed, and actively explore the artistic beauty of Singing, dancing and then by means of artistic beauty in the dissemination process advantage to ensure the song can be widely welcomed. At the same time, on the basis of the existing research on the songs, but also should pay attention to the adjustment and optimization of the song, prompting songs in contemporary society glow stronger vitality, and gradually out of the country to the world, a place in the World Music Arts Center.

\section{Reference}

[1] Wang Pingping. New Exploration of Hokkien song writing, People's Music(Review edition),2012(10):71-73.

[2] Wang Wanzhi. Discussion on beauty and charm of the tune of Hokkien song, Contemporary music, 2015(28):73-74.

[3] Li Xuanxuan. Hokkien songs' cultural inheritance and future development, Fujian Art, 2012(5):60-61. 
[4] Lin Chunchun. Popular of Hokkien songs and integration of culture new productivity, Journal of Quanzhou Normal University, 2014(3):27-30. 